\title{
Benefits of Utilizing Counseling Services Among Doctoral Women of Color in STEM
}

\section{Ms. Kairys Grasty, University of Massachusetts, Boston}

Kairys Grasty (she/her/hers) is a first-year doctoral student in the Counseling Psychology Ph.D. program at the University of Massachusetts Boston. Prior to joining this program, Kairys worked for two years as a clinical research assistant for the Center for School Mental Health in Baltimore, MD. In 2018, she moved to Boston and went on to earn her master's degree in Mental Health Counseling from UMass Boston. From the totality of her academic, clinical, and research experiences, Kairys' research interests lie in working to understand the systemic barriers, biases and insensitivities that underlie many racially and ethnically diverse people's inability or general aversion to seeking mental health support.

Ms. Shivani Sakri, Arizona State University

Shivani Sakri (she/her/hers) is a first-year doctoral student in the Engineering Education Systems and Design Ph.D. program at Arizona State University. Prior to joining this program, Shivani pursued Mechanical Engineering from the University of Pune in India and completed her Master's in Aerospace Engineering from the University of Michigan, Ann Arbor. Shivani's research interests lie in engineering control systems, experiences of women in STEM, systemic barriers and biases that dominate engineering and other STEM environments and their influence on women graduate students.

Amanda C. Arnold, Idaho State University

Dr. Jennifer M Bekki, Arizona State University

Jennifer M. Bekki is an Associate Professor in The Polytechnic School within the Ira A. Fulton Schools of Engineering at Arizona State University. Her research interests include topics related to engineering student persistence, STEM graduate students (particularly women), online learning, educational data mining, and the modeling and analysis of manufacturing systems. She holds a bachelor's degree in Bioengineering and graduate degrees in Industrial Engineering, all from Arizona State University.

\section{Dr. Kerrie G. Wilkins-Yel, University of Massachusetts, Boston}

Dr. Kerrie G. Wilkins-Yel is an Assistant Professor of Counseling Psychology at the University of Massachusetts Boston. She examines the psychological science of environmental agents that influence persistence intentions among women, particularly women of color, in STEM.

\section{Madison Natarajan, University of Massachusetts, Boston}

Madison Natarajan is a doctoral student in the Counseling Psychology Ph.D. program at University of Massachusetts Boston. Madison received her Master's of Science in Clinical Mental Health Counseling at Lipscomb University in Nashville, TN. Her research and clinical interests stem from a feminist/intersectional perspective looking at religion and sexuality, evaluating how religious identities and morals influence self-concept in the areas of sexuality, sexual expression, self-esteem, and sexual agency.

\section{Prof. Bianca L. Bernstein, Arizona State University}

Bianca L. Bernstein, Ph.D. is Professor of Counseling and Counseling Psychology in the College of Integrative Sciences and Arts at Arizona State University. Dr. Bernstein guides the CareerWISE research program, supported by the National Science Foundation since 2006. Her over 250 publications and presentations and over \$4 M in external support have focused on the application of psychological science to the career advancement of women and underrepresented minorities and the development of effective learning environments for graduate education.She is a fellow of the American Psychological Association and American Association for the Advancement of Science and has won a number of awards for her work on equity, inclusiveness and mentoring of students and faculty. Dr. Bernstein holds a bachelor's in psychology from the University of California at Berkeley and graduate degrees in Counseling Psychology from the University of California at Santa Barbara.

Dr. Ashley K. Randall, Counseling and Counseling Psychology, Arizona State University 


\title{
Benefits of Utilizing Counseling Services among Doctoral Women of Color in STEM
}

\begin{abstract}
Science, technology, engineering, and mathematics (STEM) doctoral programs are uniquely challenging for Women of Color due to the prevalence of gendered and racialized encounters. The cumulative toll of these marginalizing experiences can negatively impact graduate Women of Color's mental health and STEM persistence. The current study examines the benefits that graduate women derived from utilizing counseling services to mitigate the psychological toll of these negative encounters. Semi-structured interviews were conducted with eight racially diverse women who either completed or discontinued their STEM doctoral programs prior to completion. Participants' narratives revealed two themes: precipitating events to seek counseling and benefits of utilizing counseling, which includes three sub-themes: feeling heard, increased self-awareness, skill-building. The findings of this study highlight how counseling services are overwhelmingly positive for graduate Women of Color experiencing challenges in STEM, regardless of whether or not the decision to utilize services results in degree completion. Implications for the findings are discussed.

Keywords: STEM, counseling, mental health, graduate, Women of Color
\end{abstract}




\subsection{Introduction}

Women of Color (WOC) remain underrepresented in science, technology, engineering, and mathematics (STEM) doctoral programs. Equally concerning is that WOC who do choose to pursue a doctoral program in the physical sciences and engineering tend to leave before completing at higher rates than their White male counterparts [1]. Their daily battle with sexism, racism, and tokenism includes fielding frequent slights and insults related to their intersecting minoritized identities of gender and race/ethnicity [2], [3].

Correspondingly, WOC in STEM report needing to simultaneously justify their place in STEM while combating both gendered and racialized microaggressions [4], [5]. These experiences with racism and discrimination exacerbate and/or contribute to the onset of mental health concerns among graduate WOC in STEM [6], [7], thus adding specific urgency to a growing crisis around the mental health needs among all graduate students [8]-[10]. A recent study of 2,279 individuals (90\% Ph.D. students and 10\% Master's students) from diverse fields found that graduate students were more than six times as likely to experience depression and anxiety than the general population, with 39\% reporting moderate-severe depression and $41 \%$ reporting moderate-severe anxiety [8]. Further, graduate students in STEM disciplines are at especially high risk for experiencing mental health concerns [11]. These growing mental health concerns among graduate students remain a rarely discussed topic within STEM higher education despite reports of students expressing high stress, severe anxiety, and depression as they navigate their doctoral programs [12]. To mitigate the psychological toll of marginalizing STEM environments, graduate WOC draws on an array of coping mechanisms [13]. One such approach that has rarely been examined within the STEM context is the utilization of counseling services. Research shows that counseling can serve as a protective factor for supporting one's emotional wellbeing and program completion [9]. Findings from Murray, et al. [14] demonstrated that $63 \%$ of the students who utilized university counseling services showed reliable clinically significant improvement, thereby improving their psychological health. Although women historically have engaged in counseling services at higher rates than men [15], many within communities of color remain reticent about engaging in counseling [16]. These socio-cultural nuances, coupled with navigating a STEM culture that often renders mental health a taboo topic [17], may negatively influence WOC's utilization of counseling services, underscoring the need for more related research. 
The work presented here is part of a larger NSF-funded study within the CareerWISE research program $(\mathrm{CW})$ that aims to understand and strengthen the persistence of women in STEM doctoral programs. This paper addresses the following specific question: What benefits do WOC report from the utilization of counseling services in response to the mental health challenges they experience during their STEM doctoral programs? This research is grounded in Social Cognitive Career Theory [18], which provides a theoretical basis for understanding persistence decisions in consideration of (among other things) contextual (e.g., within the STEM environment here) supports and barriers. SCCT has broad empirical support, including for understanding and explaining experiences of WOC in STEM [19]-[21].

In this paper, we expand upon the types and sources of support for WOC commonly considered within the STEM environment -- counterspaces, mentorship, and advisor support, which all play a role in persistence decisions [3], [22] to explicitly understand the potential benefits and impact of counseling services. The findings presented here build on earlier CW research that explores the circumstances within the STEM environment that have contributed to mental health concerns among graduate WOC in STEM and the support that WOC have sought out in response to these circumstances [6].

\subsection{Methods}

\subsection{Participants}

Eligible participants for this study were women who identified as Black/African American and/or Hispanic/Latinx and/or White/Caucasian who either completed STEM doctoral degrees or chose to leave prior to completion since 2015. The data reported here consists of 8 participants who reported utilizing counseling services during their doctoral programs. Participants' ages ranged from 26 to 43 and included women who identified as Hispanic/Latinx ( $n=2)$, Black or African American $(n=3)$, and bi/multi-racial $(n=3)$. Six out of the eight participants completed their doctoral degrees, and two chose to prematurely discontinue their STEM programs before completing. Participants represented eight universities in the U.S. and six different STEM fields in the biological sciences, computer science, mathematics, and engineering. Table 1 summarizes participants' demographics, including their race/ethnicity, major, and completion status as they chose to continue (CTC) or chose to discontinue (CTD) their doctoral studies.

Table 1

Participant demographic information and program completion status

\begin{tabular}{|c|c|c|c|}
\hline Pseudonym & Race & Major & CTC/CTD \\
\hline Eva & Hispanic or Latinx & Computer Sciences & CTC \\
\hline Flavia & $\begin{array}{l}\text { Hispanic or Latinx, } \\
\text { European American or White }\end{array}$ & Engineering & CTC \\
\hline Lindsey & $\begin{array}{l}\text { Hispanic or Latinx, } \\
\text { European American or White }\end{array}$ & Biological Sciences & CTC \\
\hline Brandi & Black or African American & Mathematics & CTC \\
\hline
\end{tabular}




\begin{tabular}{llll} 
Gabriella & Hispanic or Latinx & Biological Sciences & CTD \\
Kelsey & $\begin{array}{l}\text { Black or African American, } \\
\text { Biracial }\end{array}$ & Biological Sciences & CTC \\
Flora & Black or African American & Mathematics & CTC \\
April & Black or African American & Mathematics & CTD \\
\hline
\end{tabular}

\subsection{Procedures}

Participants were screened for eligibility using an online demographic and background information survey. Women who completed their doctoral degrees were recruited from academic departments, professional associations, STEM organizations serving minoritized students, professional listservs, and alumni networks. Women who discontinued their $\mathrm{PhD}$ programs were recruited using snowball sampling, social media, and referrals from academic departments and professional networks. All participants received a \$50 gift card upon completion of their participation.

Semi-structured interviews were conducted via the Zoom video conferencing platform and ranged in length from 60 to 120 minutes. Five questions and related probes were designed to elicit participants' perceptions of support episodes at challenging times during their STEM doctoral programs. Participants were asked to identify a few specific challenging times during their doctoral studies, either academic or personal in nature, and to recall interactions they perceived as supportive or not supportive in response to the challenging circumstance. Following transcription of these interviews, each participant was invited to participate in member checking, by providing feedback about the accuracy of the transcript and adding information to clarify, correct, or supplement their responses.

\subsection{Analysis}

Phenomenological principles of qualitative data collection and interpretation guided the study in Creswell [36]. First, meaningful units (statements or examples) related to counseling experiences were identified by the research team from the transcribed interviews. Second, open coding was used to organize the data into meaningful units that resulted in two themes and four sub-themes around the impetus to seek counseling and the benefits of utilizing counseling services. The researchers reached a consensus on the results of the preliminary analysis; these results are reported here, using pseudonyms for all participants.

\subsection{Results}

Participants' narratives indicated their reasons for seeking therapy as well as several benefits from utilizing counseling services. These are summarized into two broad areas: precipitating events and benefits of seeking counseling. The latter theme consists of three sub-themes: feeling heard, increased self-awareness, and skill-building. In the following sections, we describe these themes and sub-themes and provide illustrative quotes that give voice to the variety of ways the participants experienced these counseling benefits. The four categories 
identified have been summarized in Table 2 below, with an exemplar quote in support of each of the themes.

Table 2

Emergent thematic categories and exemplar quotes

\begin{tabular}{|c|c|c|}
\hline Theme & Sub-Theme & Exemplar Quotes \\
\hline Precipitating & Events & $\begin{array}{l}\text { Kelsey (CTC): "I was depressed. That actually is what pushed } \\
\text { me into seeing a therapist there." }\end{array}$ \\
\hline \multirow[t]{3}{*}{$\begin{array}{l}\text { Benefits of } \\
\text { Utilizing } \\
\text { Counseling } \\
\text { Services }\end{array}$} & Feeling Heard & $\begin{array}{l}\text { Flavia (CTC): "It was having someone and having someone } \\
\text { to just be understood, and having someone that is invested in } \\
\text { your well-being and listening to you. There was definitely } \\
\text { not any one specific thing that flipped the switch. It was } \\
\text { really more just having an outlet." }\end{array}$ \\
\hline & $\begin{array}{l}\text { Increased } \\
\text { Self-awareness }\end{array}$ & $\begin{array}{l}\text { April (CTD): "It helped me identify how much damage my } \\
\text { negative self-talk was doing, but then it also helped me } \\
\text { separate what I was projecting onto others. My advisors } \\
\text { never told me that I was not good enough or that the quality } \\
\text { of my work was subpar... Yet, I put those ideas in my head } \\
\text { that, 'Oh, they don't really think that I can do this'." }\end{array}$ \\
\hline & Skill Building & $\begin{array}{l}\text { Flora (CTC): [In response to emotional challenges] "[My } \\
\text { counselor] helped me come up with things I could do that } \\
\text { don't take up too much time, but are still relaxing or } \\
\text { re-energizing for me... It didn't take a lot of time, but it did } \\
\text { help improve my mood. It helped me calm down." }\end{array}$ \\
\hline
\end{tabular}

\subsection{Theme \#1: Precipitating Events}

Three participants recalled events and situations during their doctoral studies which prompted their decision to seek counseling services. Kelsey (CTC) explained that when she began to experience symptoms of depression during her doctoral program, this motivated her to seek mental health services. She reported, "I was depressed. That actually is what pushed me into seeing a therapist there." Kelsey further noted that her decision to utilize counseling services was bolstered by her fear that discussing these feelings with her administrators, boss, or peers would cause her to appear incompetent. For April (CTD), she recalled that the thought of seeking counseling services initially caused her to feel hesitant and "ashamed." Yet, when her experiences in her doctoral program "got bad enough," she felt that counseling was the only option that would grant her emotional resolve. She reported,

It was that whole imposter syndrome situation where I was just like I slipped through the cracks. I don't really belong here, or I look good on paper, but that doesn't mean anything now that I'm being put to the test. Initially, no, it wasn't something I talked 
about because it was like, oh, I'll fake it until I make it. (April, Black or African American, Mathematics, CTD).

Because April's (CTD) experiences of imposter syndrome caused her to doubt her self-efficacy as a doctoral student and question her placement in her program entirely, the totality of her negative feelings led her to pursue counseling. For Brandi, (CTC) who was grappling with memories from her childhood while simultaneously trying to cope with the pressures of graduate school, this combined subset of stressors motivated her decision to seek therapy. She reported,

Yes. I went through therapy in graduate school. And I think it was partially just trying to understand... Dealing with the graduate school pressures while also dealing with some of the things from my childhood that may have shaped the reason why I'm not as confident, or the reason why I'm not performing as well...The summer before I took my third exam, I did therapy for about six weeks of that summer. (Brandi, Black or African American, Mathematics, CTC).

As Brandi (CTC) became increasingly aware of the ways in which her lack of confidence was contributing to her graduate school stress and poor performance, utilizing counseling services helped her to better understand that experience.

Although the catalysts for seeking counseling services were unique, participants' narratives indicated that these precipitating events included both challenges within the doctoral environment to challenges outside of the academic setting.

\subsection{Theme \#2: Benefits of Utilizing Counseling Services}

Participants' narratives indicated three specific benefits of counseling. These included: feeling heard, increased self-awareness, and skill building.

\subsubsection{Feeling Heard}

Four participants reported that the experience of feeling heard in counseling and the subsequent validation and support they received was something they were lacking from their other interpersonal relationships. The participants felt acknowledged and accepted by their counselor without any bias. Kelsey (CTC) explained that having someone to listen to her as " an outlet," who provided her with the space to discuss personal and professional matters was instrumental to her ability to persist through her doctoral studies. This experience was additionally supportive to Kelsey because she and the mental health professional shared the same racial identity. She reported, "So, I had a... psychiatrist, and the psychiatrist was actually an African-American woman. We talked a lot about identity as a woman, as an African-American, as an African-American woman." Thus, their shared identity allowed Kelsey to speak more openly about her lived experiences and consequently, receive greater support. Lindsey (CTC) echoed similar sentiments about how helpful it was to have the counseling center as a place to go after her mother fell ill with cancer during her doctoral studies. At that time, Lindsey reported that although she could always talk with her boyfriend about her mothers' condition, their frequent cancer conversations felt, as she described, like, "a bit of a downer" in their relationship. Thus, when talking about counseling, Lindsey explained, "having this other outlet was great, to be able to still process through that but not feel like it was taking over my whole life". Similarly, Flavia (CTC) explained how speaking 
to someone who was not in her research group or someone who she knew intimately, was helpful. She explained,

I thought about quitting so many times. And I think it was at the end of my second year that I truly, truly considered quitting. Uh, the only reason I didn't was because I had a fellowship grant from [home country's] government and if I had decided to quit, I would have to pay them back... that would just be too much. So, I just had to endure it. [But] I truly thought about quitting. And I remember, when I truly considered quitting, I even went to the counseling center to talk to a counselor. It was nice, you know, to go and talk to a counselor ... I just, yeah I had to find ways to keep going. Like I wanted to quit but I couldn't, so." (Flavia, Hispanic/Latinx, European American/White, Engineering, CTC)

Flavia's (CTC) experience provided valuable insight into how counseling services were critical for her because they permitted her to open up and express the academic stress she was experiencing. Similar to Flavia (CTC) and Kelsey (CTC), April (CTD) identified similar benefits of counseling as she reported being able to "vent and emote" resulting in a "therapeutic" feeling having been able to "flush out those emotions". Together, these participants' experiences highlighted the value of having someone with whom they could talk openly and candidly about their experiences in their doctoral studies and the respective challenges they faced.

\subsubsection{Increased self-awareness}

Three participants noted that counseling was beneficial to them because it helped them to develop increased self-awareness about their thoughts, feelings, and individual identities. April (CTD) attested to this perceived benefit when she explained how counseling helped her to become aware of her inclination to engage in negative self-talk. April (CTD) elaborated,

It was really good that I ended up doing that because it helped me separate how much ... It helped me identify how much damage my negative self-talk was doing, but then it also helped me separate what I was projecting on to others. My advisors never told me that I was not good enough or that the quality of my work was subpar. They never criticized me in that way. Yet, I put those ideas in my head...Talking to the therapist has actually helped me for those [reasons]. It was over a few months that we really teased things apart (April, Black or African American, Engineering, CTD)

As a result of the work that she did with her therapist to investigate the origins of her negative self-talk, April (CTD) was able to understand the toll that those ideas were having on her personhood, her lived experiences, and her confidence about the work she was doing. Gabriella (CTD) recalls similar experiences as she reports how counseling and her therapist's utilization of cognitive behavioral therapy helped provide her with psychoeducation about negative thoughts and the circumstances under which she experiences them. She reports,

I think one of the strategies that the university health services place, they did a lot of cognitive behavioral therapy. The most important thing that helped me was to think about those negative thoughts and try to understand what brought them. I'm going to give you an example. A very common issue I had was, "Oh, I'm not good enough. I'm just not smart enough." And one of the things that the therapist tried to tell me is, 
"When you think of that, what is it at the moment that's making you think that?" So for example, if I'm reading this paper and I don't understand it, instead of saying, " You're not smart enough," maybe it's because the paper is, like, really crappy. There is a lot of crappy articles out there. Maybe they just have a crappy article. Try to find something else. So, take those thoughts and kind of like cut them a little (Gabriella, Hispanic or Latinx, Biological Sciences, CTD).

This teaching moment was critical for Gabriella (CTD) because her therapist helped her to recognize her negative thoughts as they arose and use that newfound awareness to externalize them. It was because of this deeper understanding of this issue that Gabriella (CTD) was able to preserve a more positive view of herself that was not subject to change in the midst of her academic challenges. Brandi (CTC) similarly reported how counseling helped her to separate her academic difficulties from her personal identity. This was achieved because of her therapists' continued questioning of her beliefs about herself and her intellectual abilities, which ultimately helped increase her self-awareness. She explains,

I remember asking him [my therapist] all these questions. ... And then he just told me, he said, "I don't think it's that you don't know the material." He was like, "I just don't get that you don't know the material." He said, "I think it's deeper [than] that-it's more about personal identity, and it's more about 'Do you want this?"' ...He's like, "I can't tell you you shouldn't study, but I will say, I don't think you have to study such huge measures because you studied for the exam twice already. It's more about gaining confidence in your ability, and your self-identity, and understanding those things, and what are the things that make you you (Brandi, Black or African American, Mathematics, CTC).

With her therapist's objective perspective about her experience, Brandi (CTC) was given an opportunity to think about her experience as a doctoral student and what that meant to her, in a way that was less critical of her personal identity. Brandi (CTC) further reported that these conversations paved the way for other dialogues, such as those which centered her risks and fears and how it felt to analyze her biggest fear in the presence of her therapist. She explains, "I think at the time, my biggest fear was, if I didn't get a Ph.D., what would people think of me? And he told me that my... Getting the Ph.D. is not tied to my self-worth." Brandi's (CTC) experience demonstrates how her conversations with her therapist helped her to dismantle her beliefs about how her self-worth was contingent upon her Ph.D. identity. Brandi's (CTC) experience and others illuminated the benefits of the counseling relationship in attaining a level of insight about their identities that ultimately contributed to their ability to cope with the challenges they faced during their doctoral studies.

\subsubsection{Skill building}

Additionally, three participants reported that counseling was useful to them because of the skill building that it encompassed, such as learning new relaxation techniques and interpersonal skills when faced with personal and interpersonal difficulties. Flora (CTC) attested to this benefit of counseling when her therapist asked her to write down her schedule for the week, which revealed that Flora (CTC) was allocating the vast majority of her time to studying, "I was not doing anything recreational, at all," she explained. When she recognized this, Flora's (CTC) therapist helped her to manufacture a list of short mechanisms that she could employ that would help to relax and re-energize her. She explained, 
Like one of the things was, in the morning when I'm getting ready, I can play music that I enjoy, upbeat music, or music that is fun. And to this day, I mean it didn't take a lot of time, but it did help improve my mood. It helped me calm down, a little. (Flora, Black or African American, Mathematics, CTC)

This incremental incorporation of music into her day, as suggested by her therapist, was profound for Flora (CTC) because it was a skill to bring about feelings of calm and improve her mood that she did not know were at her disposal before. Because of her therapist, she now had a tool that she could use to disrupt the rigor of her academic demands, while simultaneously helping herself to feel refreshed and ready to tend to them. Gabriella (CTD) similarly details that, as a result of working with a therapist, she acquired skills that helped her to control distressing emotions as they arose during her doctoral studies. This was particularly useful for her, as she reported,

For the times that I depersonalized or had panic attacks, I had to learn breathing techniques, and they helped me with that. Like how to cut a thought, because most of it is my body just reacting to a thought, and then that circle of the mind thinks something, the body reacts, oh, you're going to die, let's just, like, kick the whole cycle again. (Gabriella, Hispanic or Latinx, Biological Sciences, CTD).

As a result of this skill, Gabriella (CTD) was able to contain her presenting mental health concerns that had previously been taking a toll on her lived experience as a doctoral student. Similarly, for Flavia (CTC), counseling was critical to strengthening her interpersonal skills because her therapist helped her to establish boundaries. She explains,

One thing I remember, she [her therapist] showed me, like in our first session... I don't remember exactly what it was called but it was this list of 10 rights you have or, I don't remember the exact name. But one of the things that was on this list was like you have rights to set boundaries and I remember that being the most helpful thing. Cause, it seems obvious, right, to always do, but it wasn't, you know. It wasn't until, you know, I had someone tell me 'It's okay to set boundaries, it's okay to have boundaries with your advisor, it's okay to have boundaries with your lab mates. But I could actually see that I needed to work on that. That I needed to set more boundaries on my work environment, you know. (Flavia, Hispanic or Latinx, European American or White, Engineering, CTC).

Flavia's (CTC) therapist's objective reiteration of the importance of boundaries helped her to recognize how critical boundaries were and come to terms with how much she was lacking them in her everyday life. With this information, Flavia (CTC) was given the means to navigate negative interpersonal interactions with her STEM lab mates.

It is evident across the participants' narratives that their engagement with counseling and the skills that they acquired as a result, were factors that helped them to manage their competing academic expectations and the emotional challenges that arose in their efforts to do so.

\subsection{Summary}

The academic and personal challenges that graduate WOC encountered during their STEM doctoral programs had the potential to obstruct their persistence in STEM and cause them to experience emotional distress. For these reasons, participants sought to utilize 
mental health counseling services at their respective institutions. The outcome of this decision was positive for all of the study participants. Specifically, participants reported that after seeking counseling services, they felt supported, heard, and developed a better understanding of themselves. For five of the seven participants, it can be deduced that their engagement with services was a factor that contributed to the continuation of their doctoral pursuits. In other cases, although participants reported that they similarly experienced counseling services as positive and derived many benefits from it, the benefits were not profound enough to mitigate against the stressors and irreparable negative outcomes they had accrued in STEM spaces. For this small subset of participants, their engagement with counseling services was the action step that allowed them to feel more comfortable in their decision to discontinue their doctoral pursuits.

\subsection{Discussion}

The current study sought to understand how one form of coping -- the utilization of counseling services -- supported graduate WOC in STEM. The results suggested that counseling services can serve as an effective avenue for helping WOC in STEM doctoral programs cope with academic and personal challenges that might have had the potential to interfere with their degree completion. These findings are not unexpected given that the current body of literature has found that the utilization of counseling services has served as a protective factor for graduate students [6], [9]. In the data reported here, the participants' experiences of counseling were in alignment with prior investigations on its perceived benefits.

Specifically, when graduate women in STEM had a mental health professional with whom they could talk to, it helped them better manage the pressures and expectations of their doctoral studies [23]. For example, the mounting stress of the doctoral studies contributed to Flavia (CTC), considering discontinuing her doctoral program. Although the financial repercussions of repaying her fellowship eventually deterred her from discontinuing, Flavia (CTC) valued having an outlet to express these complex emotions. So, with very few options to turn to for support in her everyday life, Flavia (CTC) experienced counseling as a valuable tool in seeking support. Similarly, Eva (CTC) also credited the counseling services for the support that they were able to provide because, at the time of her studies, her peers and siblings were not living in the country. In the absence of her primary social supports, Eva (CTC) explained that counseling was a place that offered reassurance and tangible emotional solace to her during her doctoral studies, as she was able to speak to someone physically and express her emotions. The participants' experiences highlight and fortify our understanding of how counseling services provided the participants with support. For Brandi (CTC), counseling not only helped her to navigate the academic and interpersonal challenges that arose during her doctoral studies, but also helped to remind her of her self-efficacy as a student. She explained that conversations with her counselor helped her to realize her confidence in her abilities, as well as recognize that her self-worth is not determined by the acquisition of the doctorate degree. With this insight from her counselor, Brandi (CTC) was able to approach graduate school stressors with a clearer mind and continue on with the completion of her degree.

The ways in which counseling helped three of the participants to make persistence related decisions is another testament to its usefulness amongst graduate WOC in STEM. Although women in STEM graduate programs are more likely to have experiences within that environment that threaten their identity, self-esteem, and self-efficacy [24], their 
persistence in their respective graduate programs is also at risk as a result of the conflating academic and emotional stressors. For Flavia (CTC), her experience of stress became so intolerable that she considered quitting. However, she explained how leaving the doctorate program was not an option for her as the financial repercussions of quitting would be too severe. Due to Flavia's (CTC) inability to liberate herself from her circumstance, she explained that counseling was helpful at that time because having someone to talk to helped her persist through her degree program. Thus, counseling was an instrumental vehicle to Flavia (CTC) and the other women because it helped them to remain in their respective programs and better manage the stressors and negative feelings that they were experiencing during their doctoral studies.

Our findings are a novel contribution to the literature on the utilization of counseling amongst WOC in STEM because WOC have historically been resistant to seek mental health services because of the stigma surrounding mental illness in communities of color and the cultural mistrust that has been prominent in minoritized communities [25]. In particular, Black or African American women's reluctance to utilize mental health services has also been influenced by the Strong Black Woman (SBW) stereotype, which perpetuates the belief that Black women need to appear strong and emotionally resilient when faced with incredible challenges or experiences of stress [26]. Thereby, the decision to seek support is more likely to be put off [27]. For Hispanic or Latinx women, their reported hesitation to seeking counseling stems from the cultural belief that mental illness brings about shame and embarrassment to the individual who is afflicted, and therefore it is not meant to be discussed with members' outside of one's immediate family [27]. Yet, in spite of the cultural taboo that surrounds the utilization of mental health services in racially and ethnically diverse communities, the eight WOC sought out counseling and collectively described the experience as helpful.

Our findings are further explained through the Social Cognitive Career Theory theoretical framework [18], which highlights that although academic and career interests are developed and subsequently pursued depending on an individuals' interests and inherent values, their ability for those career developments to be achieved can be impacted by environmental factors as well. For the participants in our study, the academic pressures and mental health challenges that they faced during their STEM degree programs had the potential to stifle their career development. But through the utilization of counseling services and the new awareness they gained about themselves and their self-efficacy as students in higher education, the career directness and goals were revitalized. It is important to note that negative STEM environments rife with systemic barriers need to be changed. Further, it is not a woman's responsibility to dismantle these marginalizing environments. While this much-needed overhaul of STEM is underway, resources like counseling services can be helpful in supporting minoritized students to address the toll of these negative STEM cultures.

Given the qualitative nature of this study, these results are not generalizable to samples beyond the eight women in this study. This is standard practice for qualitative research because, conversely to quantitative research, statistical-probabilistic generalizability and broad inferences are not the desired outcomes [28]. Instead, qualitative research seeks to gain a deeper understanding of an individual's experience of an event by gathering the rich contextual elements and nuances that contribute to that experience [29]. Thus, small samples and in-depth interview methods are purposeful because the concern lies in understanding the experience intimately, rather than collecting evidence of its generalizability. Thus, the data 
collected here and the unique meaning that the graduate WOC derived from seeking counseling, attests to the novelty of these results.

\subsection{Implications \& Conclusion}

WOC not only endure the subset of stressors that are customary to pursuing a graduate degree but they are also subjected to supplemental race- and gender-based discriminatory interactions within their STEM environments. The eight graduate WOC collectively attested to how the utilization of counseling services buffered the impact of these experiences during graduate school. This study demonstrates that WOC in STEM do have the potential to derive benefits and distress tolerance skills from counseling. The majority of the participants reported that feeling heard and having increased self-awareness were among the most common benefits obtained from this experience. The participants' own due diligence in seeking support services in this study is also notable.

The chilly and unwelcoming nature of STEM environments have historically served to ostracize women, undermine their confidence in themselves as STEM professionals, and relied upon stereotypes and other discriminatory tactics to challenge their rights to exist in those spaces [30]. Given that STEM spaces can be detrimental for women, especially for WOC who are exposed to dual marginalization on the basis of their gender and racial identities, the implications for our investigation are as follows. Advisors and administrators within STEM doctoral programs have a responsibility to be more attuned to the emotional distress and mental health challenges that WOC face in their doctoral pursuits, as their non-academic related support has been found to contribute to students' general sense of well-being [31]. Recognizing the signs of distress, such as excessive procrastination, a decrease in the quality of a students' work, listlessness in class, impaired speech, and disjointed thoughts are all marked cues that can be indicative of a students' need for mental health support [32]. Emotional distress in students can also present as flat affect, incongruous affect, crying, a lack of follow through with assignments, or a general inability to describe their own emotional state [33].

In the presence or absence of these signs, advisors should be aware of the mental health resources that exist on campus, their hours of operation, how appointments can be scheduled, and how students can be referred for a higher level of care. Advisors and related faculty should also ensure that this information is made readily accessible to all students, which would necessitate having a conversation with them about it. This dialogue would help to normalize the experience of utilizing counseling as a support resource, while simultaneously fostering comfort around discussing mental health challenges and emotional distress. When advisors initiate these conversations and provide role-appropriate psychosocial support, advisees have been found to cope better with the distressing emotions that arise during their degree pursuits and report increased satisfaction with their doctoral programs entirely [34], [35]. Thus, our findings illustrate how counseling services can be beneficial to the WOC in STEM that chose to utilize them, and to advisors and administrators within STEM degree programs who are chiefly responsible for protecting students from discriminatory experiences. 


\section{Acknowledgment}

This study was supported by the National Science Foundation (NSF) grants 1761278 and 2019533. Any opinions, findings, and conclusions, and recommendations expressed in this report are those of the authors and do not necessarily reflect the views of the NSF. 


\section{References}

[1] R. Sowell, Doctoral Initiative on Minority Attrition and Completion., Washington, DC: Council of Graduate Schools, 2015.

[2] M. Ong, C. Wright, L. L. Espinosa, and G. Orfield, "Inside the double bind: A Synthesis of empirical research on undergraduate and graduate women of color in science, technology, engineering, and mathematics," Harv. Educ. Rev., vol. 81, no. 2, pp. 172-208, Jun. 2011, doi: 10.17763/haer.81.2.t022245n7x4752v2.

[3] M. Cabay, B. L. Bernstein, M. Rivers, and N. Fabert, "Chilly climates, balancing acts, and shifting pathways: What happens to women in STEM doctoral programs," Soc. Sci., vol. 7, no. 2, p. 23, Jan. 2018, doi: 10.3390/socsci7020023.

[4] D. R. Johnson, "Women of color in science, technology, engineering, and mathematics (STEM)," New Dir. Institutional Res., vol. 2011, no. 152, pp. 75-85, Dec. 2011, doi: 10.1002/ir.410.

[5] K. G. Wilkins-Yel, J. Hyman, and N. O. O. Zounlome, "Linking intersectional invisibility and hypervisibility to experiences of microaggressions among graduate women of color in STEM," J. Vocat. Behav., vol. 113, pp. 51-61, Aug. 2019, doi: 10.1016/j.jvb.2018.10.018.

[6] A. C. Arnold et al., "Examining the effects of STEM climate on the mental health of graduate women from diverse racial/ethnic backgrounds," in ASEE Annual Conference and Exposition, Conference Proceedings, Jun. 2020, vol. 2020-June, doi: 10.18260/1-2--34617.

[7] L. Torres, M. W. Driscoll, and A. L. Burrow, "Racial microaggressions and psychological functioning among highly achieving African-Americans: A mixed-methods approach,” J. Soc. Clin. Psychol., vol. 29, no. 10, pp. 1074-1099, Dec. 2010, doi: 10.1521/jscp.2010.29.10.1074.

[8] T. M. Evans, L. Bira, J. B. Gastelum, L. T. Weiss, and N. L. Vanderford, "Evidence for a mental health crisis in graduate education," Nat. Biotechnol., vol. 36, no. 3, pp. 282-284, Mar. 2018, doi: 10.1038/nbt.4089.

[9] J. K. Hyun, B. C. Quinn, T. Madon, and S. Lustig, "Graduate student mental health: Needs assessment and utilization of counseling services," J. Coll. Stud. Dev., vol. 47, no. 3, pp. 247-266, May 2006, doi: 10.1353/csd.2006.0030.

[10] C. M. Rummell, "An exploratory study of psychology graduate student workload, health, and program satisfaction," Prof. Psychol. Res. Pract., vol. 46, no. 6, pp. 391-399, Dec. 2015, doi: 10.1037/pro0000056. 
[11] M. Deziel, D. Olawo, L. Truchon, and L. Golab, “Analyzing the Mental Health of Engineering Students using Classification and Regression,” 2013, p. 228231.

[12] E. Hocker, E. Zerbe, and C. G. P. Berdanier, "Characterizing Doctoral Engineering Student Socialization: Narratives of Mental Health, Decisions to Persist, and Consideration of Career Trajectories," in Proceedings - Frontiers in Education Conference, FIE, Oct. 2019, vol. 2019-October, pp. 1-7, doi: 10.1109/FIE43999.2019.9028438.

[13] D. L. Brunsma, D. G. Embrick, and J. H. Shin, "Graduate Students of Color," Sociol. Race Ethn., vol. 3, no. 1, pp. 1-13, Jan. 2017, doi: 10.1177/2332649216681565.

[14] A. L. Murray, K. McKenzie, K. R. Murray, and M. Richelieu, "An analysis of the effectiveness of university counseling services," Br. J. Guid. Couns., vol. 44, no. 1, pp. 130-139, Jan. 2016, doi: 10.1080/03069885.2015.1043621.

[15] M. E. Addis, "Gender and depression in men," Clinical Psychology: Science and Practice, vol. 15, no. 3. pp. 153-168, Sep. 2008, doi: 10.1111/j.1468-2850.2008.00125.x.

[16] A. M. Cauce et al., "Cultural and contextual influences in mental health help seeking: A focus on ethnic minority youth," Journal of Consulting and Clinical Psychology, vol. 70, no. 1. American Psychological Association Inc., pp. 44-55, 2002, doi: 10.1037/0022-006X.70.1.44.

[17] M. P. S. Mousavi et al., "Stress and Mental Health in Graduate School: How Student Empowerment Creates Lasting Change," J. Chem. Educ., vol. 95, no. 11, pp. 1939-1946, Nov. 2018, doi: 10.1021/acs.jchemed.8b00188.

[18] R. W. Lent, S. D. Brown, and G. Hackett, "Toward a Unifying Social Cognitive Theory of Career and Academic Interest, Choice, and Performance," Journal of Vocational Behavior, vol. 45, no. 1. pp. 79-122, Aug. 1994, doi: 10.1006/jvbe.1994.1027.

[19] A. Byars-Winston, Y. Estrada, C. Howard, D. Davis, and J. Zalapa, "Influence of Social Cognitive and Ethnic Variables on Academic Goals of Underrepresented Students in Science and Engineering: A Multiple-Groups Analysis," J. Couns. Psychol., vol. 57, no. 2, pp. 205-218, Apr. 2010, doi: 10.1037/a0018608.

[20] H. S. Lee, L. Y. Flores, R. R. Navarro, and M. Kanagui-Muñoz, “A longitudinal test of social cognitive career theory's academic persistence model among Latino/a and White men and women engineering students," J. Vocat. Behav., vol. 88, pp. 95-103, Jun. 2015, doi: 10.1016/j.jvb.2015.02.003.

[21] R. L. Navarro, L. Y. Flores, H.-S. Lee, and R. Gonzalez, "Testing a longitudinal social cognitive model of intended persistence with engineering students across gender and 
race/ethnicity," J. Vocat. Behav., vol. 85, no. 1, pp. 146-155, Aug. 2014, doi: 10.1016/j.jvb.2014.05.007.

[22] A. E. Dawson, B. L. Bernstein, and J. M. Bekki, "Providing the Psychosocial Benefits of Mentoring to Women in STEM: Career WISE as an Online Solution," New Dir. High. Educ., vol. 2015, no. 171, pp. 53-62, Sep. 2015, doi: 10.1002/he.20142.

[23] E. D. Reilly, G. H. Awad, M. M. Kelly, and A. B. Rochlen, "The Relationship Among Stigma Consciousness, Perfectionism, and Mental Health in Engaging and Retaining STEM Women," J. Career Dev., vol. 46, no. 4, pp. 443-457, Aug. 2019, doi: $10.1177 / 0894845318784745$.

[24] B. J. Casad, Z. W. Petzel, and E. A. Ingalls, “A Model of Threatening Academic Environments Predicts Women STEM Majors' Self-Esteem and Engagement in STEM," Sex Roles, vol. 80, no. 7-8, pp. 469-488, Apr. 2019, doi: 10.1007/s11199-018-0942-4.

[25] E. C. Ward, L. O. Clark, and S. Heidrich, "African American women's beliefs, coping behaviors, and barriers to seeking mental health services," Qual. Health Res., vol. 19, no. 11, pp. 1589-1601, Nov. 2009, doi: 10.1177/1049732309350686.

[26] R. A. Donovan and L. M. West, "Stress and Mental Health: Moderating Role of the Strong Black Woman Stereotype," J. Black Psychol., vol. 41, no. 4, pp. 384-396, Aug. 2015, doi: 10.1177/0095798414543014.

[27] E. Wong, R. Collins, J. Cerully, R. Seelam, and E. Roth, Racial and Ethnic Differences in Mental Illness Stigma and Discrimination Among Californians Experiencing Mental Health Challenges, vol. 6, no. 2. RAND Corporation, 2016.

[28] D. F. Polit and C. T. Beck, "Generalization in quantitative and qualitative research: Myths and strategies," Int. J. Nurs. Stud., vol. 47, no. 11, pp. 1451-1458, Nov. 2010, doi: 10.1016/j.ijnurstu.2010.06.004.

[29] B. Smith, "Generalizability in qualitative research: misunderstandings, opportunities and recommendations for the sport and exercise sciences," Qual. Res. Sport. Exerc. Heal., vol. 10, no. 1, pp. 137-149, Jan. 2018, doi: 10.1080/2159676X.2017.1393221.

[30] H. Blackburn, "The Status of Women in STEM in Higher Education: A Review of the Literature 2007-2017," Sci. Technol. Libr., vol. 36, no. 3, pp. 235-273, Jul. 2017, doi: 10.1080/0194262X.2017.1371658.

[31] E. Waight and A. Giordano, “Doctoral students' access to non-academic support for mental health,” J. High. Educ. Policy Manag., vol. 40, no. 4, pp. 390-412, Jul. 2018, doi: 10.1080/1360080X.2018.1478613. 
[32] Office of Student Life Studies, “ Noncognitive factors that influence student learning. A Quarterly Summary of Challenges to Student Learning”, vol. 4, pp. 1-3. Cape Girardeau, MO: Southeast Missouri State University. Retrieved from http://www5.semo.edu/stulifestudies/nov00.pdf

[33] R. Harper and M. Peterson, "Mental health issues and college students," 2005.

[34] D. R. Primé, B. L. Bernstein, K. G. Wilkins, and J. M. Bekki, "Measuring the Advising Alliance for Female Graduate Students in Science and Engineering: An Emerging Structure," J. Career Assess., vol. 23, no. 1, pp. 64-78, Feb. 2015, doi: $10.1177 / 1069072714523086$.

[35] C. M. Zhao, C. M. Golde, and A. C. McCormick, "More than a signature: How advisor choice and advisor behavior affect doctoral student satisfaction," J. Furth. High. Educ., vol. 31, no. 3, pp. 263-281, Aug. 2007, doi: 10.1080/03098770701424983.

[36] J. W. Creswell, Qualitative Inquiry and Research Design, SAGE Publications, 2013. 